\title{
A Study on the Spectrum of Neonatal Intestinal Obstruction in a Tertiary Care Centre
}

\author{
Amarendra Nath Sarkar ${ }^{1}$, Partha Pratim Deb ${ }^{2 *}$, Surajit Paul ${ }^{3}$
}

\author{
${ }^{1}$ Associate Professor, Department of General Surgery, North Bengal Medical College, Darjeeling, India \\ ${ }^{2}$ RMO cum Clinical Tutor, Department of General Surgery, North Bengal Medical College, Darjeeling, India \\ ${ }^{3} \mathrm{RMO}$ cum Clinical Tutor, Department of General Surgery, North Bengal Medical College, Darjeeling, India
}

DOI: $10.36347 /$ sjams.2021.v09i02.010

| Received: 27.01.2021 | Accepted: 13.02.2021 | Published: 18.02.2021

*Corresponding author: Partha Pratim Deb

Abstract

Original Research Article

\begin{abstract}
Neonatal intestinal obstruction is a common surgical emergency requiring intervention in newborn. This study was conducted amongst 40 diagnosed cases of neonatal intestinal obstruction admitted in the department of general surgery and paediatric medicine of North Bengal Medical College and Hospital during the study period. 1 out of every 156 neonates admitted in this hospital during the study period was a case of neonatal intestinal obstruction. There was a male preponderance with a male-female ratio of $3: 1 \quad(\mathrm{p}<0.0001) .15 \%$ of neonates suffered from prematurity. Gestational age varied from 32 weeks to 42 weeks. $70 \%$ of neonates were below $2.5 \mathrm{~kg}$ at presentation $(\mathrm{p}=0.0003)$. Majority of neonates $(55 \%)$ presented within 7 days of birth $(\mathrm{p}=0.3711)$. Most of the cases of anorectal malformations, intestinal atresia and meconium ileus presented within first week of birth while rest presented after 7 days. $45 \%$ of the neonates suffered from anorectal malformation, 25\% suffered from Hirschsprung disease while $22.5 \%$ suffered from intestinal atresia. Other causes were malrotation and meconium ileus. Amongst anorectal malformations, high anomalies were commoner than low anomalies in this study $(\mathrm{p}<0.0001)$. Abdominal distension, failure to pass meconium within 24 hours, vomiting, constipation, absent anal opening was the common symptoms at presentation. There were $17.5 \%$ cases of complications following surgery for intestinal obstruction and majority of them were due to superficial wound infections. The mortality rate in our study was $12.5 \%$ and highest cases of mortality were seen in cases of intestinal atresia.

Keywords: Neonatal, Intestinal, Obstruction, Anorectal, Malformation.

Copyright $($ C) 2021 The Author(s): This is an open-access article distributed under the terms of the Creative Commons Attribution 4.0 International License (CC BY-NC 4.0) which permits unrestricted use, distribution, and reproduction in any medium for non-commercial use provided the original author and source are credited.
\end{abstract}

\section{INTRODUCTION}

Neonatal intestinal obstruction is one of the most common newborn surgical emergencies [1] that occur in 1 in 1500 live birth [2]. Unlike in adults or older children, the majority are due to congenital causes [3]. Successful management of a newborn with intestinal obstruction depends on timely diagnosis and prompt management [4]. The attendant pathological sequalae which progresses rapidly to irreversible complication is poorly tolerated by the newborns. Failure to recognize neonatal bowel obstruction can result in aspiration of vomitus, sepsis, midgut infarction or perforation and enterocolitis [5].

The aetiology of neonatal intestinal obstruction, its presentation, attendant morbidity and outcome of treatment vary significantly between centres $[6,7]$. Common causes of neonatal intestinal obstruction are intestinal atresia, meconium ileaus, anorectal malformation (ARM), hirschsprung's disease and malrotation of gut with or without volvulus. The principal features of neonatal intestinal obstruction are bile-stained vomiting, failure to pass meconium and abdominal distension. Early vomiting in the first 24 hours of life indicates a high obstruction (duodenal or jejunal) while the later onset of vomiting indicates a lower obstruction (ileal or colonic) [8].

The management of neonatal intestinal obstruction in developing countries remains challenging with poorer outcome compared to the results from the developed countries $[9,10]$. Some factors attributing to the high mortality in developing countries includes prematurity, late presentation, associated severe congenital anomalies and complications of surgery as well as lack of intensive care facilities $[1,9,11]$. This is compounded by lack of basic facilities for proper surgical management of neonates, poor socioeconomic 
Amarendra Nath Sarkar et al; Sch J App Med Sci, Feb, 2021; 9(2): 223-226

status of parents and cultural belief and poor attitude towards neonates born with surgical pathology [12].

This is a prospective study of cases of neonatal intestinal obstruction admitted at non-specialised neonatal surgical set up of north Bengal medical college and hospital, Darjeeling.

\section{Material And Methods}

A prospective study was conducted in the department of general surgery and paediatric medicine of north Bengal medical college and hospital, Darjeeling for a period of one year. At least 40 patients diagnosed as neonatal intestinal obstruction within the study period were enrolled for the study. Parents of the neonates were interviewed after taking informed consent; antenatal records were checked, thorough examination of the neonates from head to toe for anthropometric assessment and clinical examination and investigations accordingly for identification of cases and associated anomalies.

All cases were immediately resuscitated and stabilized before surgery. Findings of the investigations (routine lab tests for blood and urine and imaging in the form of x- ray of abdomen, barium enema, invertogram and ultrasound whichever appropriate), surgical intervention and reports of histopathological examinations were recorded. All cases received optimal post-operative care to decrease post-operative morbidity and mortality.

Data was collected on a semistructured proforma and analysed for age, sex, weight, type of gestation/gestational age at birth/mode of delivary, aetiology, clinical presentation, associated anomaly, treatment and outcome. Data was analysed using standard statistical methods and software.

\section{RESULTS}

During the study period, 6252 neonates were admitted in the department of general surgery and paeditric medicine of our hospital. Amongst them 98 babies required surgical intervention. 40 out of these 98 neonates $(40.8 \%)$ were cases of neonatal intestinal obstruction requiring surgery to relieve obstruction i,e 1 out of 156 neonates admitted was a case of neonatal intestinal obstruction.

Table-1: Analysis of data according to sex, age, body weight and prematurity

\begin{tabular}{|l|l|l|}
\hline factors & Divisions & $\mathbf{N}(\%)$ \\
\hline Sex & Male & $30(75)$ \\
& Female & $10(25)$ \\
\hline Age at presentation & $1-7$ days & $22(55)$ \\
& 8-14days & $12(30)$ \\
& $15-21$ days & $4(10)$ \\
& $22-28$ days & $2(5)$ \\
\hline Body weight at presentation & $<2.5 \mathrm{~kg}$ & $28(70)$ \\
& >or=2.5kg & $12(30)$ \\
\hline Prematurity & Male & $4(13.3)$ \\
& Female & $2(20)$ \\
\hline
\end{tabular}

Out of the 40 cases, 30(75\%) were male whereas $10(25 \%)$ were female. The difference was found to be statistically significant $(\mathrm{p}<0.0001) .22(55 \%)$ neonates presented within 7 days of birth while $12(30 \%), 4(10 \%)$ and $2(5 \%)$ neonates presented during the second, third, fourth week of life respectively but this was not statistically significant $(\mathrm{p}=0.3711)$. Most of the cases of ARM, intestinal atresia and meconium ileus presented within 1 week of birth while rest presented after 7 days. $28(70 \%)$ neonates weighed below $2.5 \mathrm{kgs}$ at the time of presentation whereas $12(30 \%)$ neonates weighed more than $2.5 \mathrm{kgs}$ and this was found to be statistically significant $(\mathrm{p}=0.0003)$. In our study $6(15 \%)$ neonates suffered from prematurity. Of them 4 were boys and 2 were girls. Gestational age varied from 32 weeks to 42 weeks.

Abdominal distension, failure to pass meconium within first 24 hours, vomiting, constipation, absent anal opening was the common symptoms at presentation. In our study, $45 \%$ suffered from anorectal malformation, $25 \%$ from hirschsprung's disease, and $22.5 \%$ from intestinal atresia as shown in table 2 . Among patients of intestinal atresia, $10 \%$ were jejunoileal atresia, 5\% were cases of duodenal atresia, and $5 \%$ were colonic atresia, malrotation and meconium ileus accounted for $7.5 \%$ and $2.5 \%$ neonates respectively. Among patients of ARM, high anomalies were commoner than low anomalies. $70.5 \%$ neonates presented with high anomalies whereas $29.5 \%$ neonates presented with low anomalies and this was statistically significant $(\mathrm{p}<0.0001)$.

Table-2: causes of intestinal obstruction among study population

\begin{tabular}{|l|l|l|l|}
\hline causes & Incidence (n) & \%age & Mortality \\
\hline $\begin{array}{l}\text { ARM i) high(13) } \\
\text { ii) low(5) }\end{array}$ & 18 & 45 & 1 \\
\hline Hirschsprung's disease & 10 & 25 & 0 \\
\hline Duodenal atresia & 2 & 5 & 0 \\
\hline Jejunoileal atresia & 4 & 10 & 3 \\
\hline Colonic atresia & 2 & 5 & 0 \\
\hline malrotation & 3 & 7.5 & 1 \\
\hline Meconium ileus & 1 & 2.5 & 0 \\
\hline
\end{tabular}


Amarendra Nath Sarkar et al; Sch J App Med Sci, Feb, 2021; 9(2): 223-226

There were $7(17.5 \%)$ cases of complications following surgery for intestinal obstruction. Majority of the cases were superficial wound infection (3 cases) which were treated with local wound care and antibiotics. Other complications encountered were stoma retraction, stoma stenosis and anastomotic dehiscence. The mortality rate in this study was $12.5 \%$ (5 cases). The highest was in cases of jejunoileal atresia ( 3 cases) among which 2 cases were due to septicaemia and 1 case was due to reoperation. This was followed by malrotation with strangulation ( 1 case) due to septicaemia and another in case of high anorectal malformation due to aspiration pneumonia.

\section{DISCUSSION}

Intestinal obstruction in neonates is usually acute and is the most common surgical emergency in them [13]. The present study is an attempt to study the cases, clinical presentation and management of intestinal obstruction in neonates at north Bengal medical college and hospital in darjeeling, west Bengal.

In the present study, a male preponderance (M: $\mathrm{F}=3: 1)$ was noted among the 40 neonates included in the study. Similar male preponderance was noted in a study by Gangopadhyay AN et al. [13] where a male: female ratio of almost 6:1 was found in study conducted among 765 neonates.
In our study, most of the cases of ARM, intestinal atresia and meconium ileus presented within first week of birth while rest presented after 7 days. Similarly, in a study by A. K. Saha et al. [14], 133 $(64.9 \%)$ neonates presented within 7 days of birth and majority of the neonates with ARM, intestinal atresia and meconium ileus presented within first week of their life. On the other hand, neonates with hirschsprung's disease and malrotation presented later on.

In our study, $70 \%$ (28) of the neonates were below $2.5 \mathrm{kgs}$ which is similar to a study by Gangopadhyay AN et al. [13] where $81.1 \%$ of cases were below $2.5 \mathrm{kgs}$ while rest were above $2.5 \mathrm{kgs}$.

In the present study, $15 \%$ (6) of neonates were premature with a male preponderance ( 4 boys and 2 girls). Similarly in the study by A.K.Saha et al. [13] among 205 neonates only 13\% (24) of neonates were premature with a male preponderance.

Osarumwense David Osifo et al. [15] showed that clinical presentation of neonatal intestinal obstruction included abdominal distension in $97.2 \%$ of neonates, failure to pass meconium in $91.5 \%$, vomiting in $60.6 \%$, constipation in $35 \%$ and absent anal opening in $35 \%$ cases. The present study showed similar observations also.

Table-3: Comparative analysis of causes of intestinal obstruction

\begin{tabular}{|l|l|l|l|l|}
\hline causes & $\begin{array}{l}\text { Gangopadhyay AN } \\
\text { et al. India (N=765) }\end{array}$ & $\begin{array}{l}\text { Kadim AH } \\
\text { et al. Iraq } \\
(\mathbf{N = 3 6 )}\end{array}$ & $\begin{array}{l}\text { Ameh EA et al. } \\
\text { Nigeria(N=151) }\end{array}$ & $\begin{array}{l}\text { Present } \\
\text { study(N=40) }\end{array}$ \\
\hline Anorectal anomalies & $385(50.3 \%)$ & $10(27.8 \%)$ & $104(68.7 \%)$ & $18(45 \%)$ \\
\hline Hirschsprung's disease & $115(15.7 \%)$ & 0 & $11(7.3 \%)$ & $10(25 \%)$ \\
\hline Intestinal atresia & $60(7.8 \%)$ & $14(38.8 \%)$ & $10(6.7 \%)$ & $8(20 \%)$ \\
\hline Malrotation & $45(5.9 \%)$ & $2(5.5 \%)$ & $6(4 \%)$ & $3(7.5 \%)$ \\
\hline Intussuception & $30(4 \%)$ & $1(2.7 \%)$ & 0 & 0 \\
\hline Meconium ileus & $15(2 \%)$ & $4(11.1 \%)$ & $4(2.6 \%)$ & $1(2.5 \%)$ \\
\hline Incarcerated hernia & $77(10 \%)$ & $1(2.7 \%)$ & $11(7.5 \%)$ & 0 \\
\hline Meckel's diverticulum & $20(2.5 \%)$ & 0 & $3(2 \%)$ & 0 \\
\hline Meconium plug syndrome & $8(1 \%)$ & 0 & 0 & 0 \\
\hline Necrotizing enterocolitis & $10(1.3 \%)$ & 0 & 0 & 0 \\
\hline
\end{tabular}

In this study, ARM was the most common cause of intestinal obstruction in neonates. 18(45\%) neonates out of 40 suffered from anorectal malformation. 10(25\%) neonates suffered from Hirschsprung's disease. 9(22.5\%) neonates suffered from intestinal atresia. Of them $4(10 \%)$ were cases of jejuno-ileal atresia, $2(5 \%)$ were cases of duodenal atresia and 2(5\%) were cases of colonic atresia. Malrotation and meconium ileus account for 3(7.5\%) and $1(2.5 \%)$ neonates respectively. Gangopadhyay et al. [14] showed similar results with anorectal anomalies $(50.3 \%)$ being the leading cause followed by hirschsprung disease $(15.7 \%)$, bowel atresia $(7.8 \%)$ and malrotation of gut $(5.9 \%)$. Study done by Kadim AH et al. [10] among 36 neonates found intestinal atresia as the main cause of the obstruction $(27.8 \%)$ followed by imperforate anus $(27.8 \%)$, meconium ileus $(11.1 \%)$, necrotising enterocolitis $(8.33 \%)$, malrotation and intussuception. The reason for this difference could be due to environmental and ethnic causes. In the study by Ameh EA et al. [9] among 151 neonates, anorectal malformations $(68.9 \%)$ were the most common cause followed by hirschsprung's disease $(7.3 \%)$, incarcerated hernia (7.3\%), and intestinal atresia (6.7\%). Other less common causes in their study were incarcerated exomphalos, malrotation, annular pancreas, and idiopathic ileal volvulus and meconium ileus. 
Amarendra Nath Sarkar et al; Sch J App Med Sci, Feb, 2021; 9(2): 223-226

\section{CONCLUSiON}

Intestinal obstruction amongst neonates is a common surgical emergency which requires a team approach for optimal outcome as the causes of obstruction are congenital. Abdominal distension, failure to pass meconium within first 24 hours, vomiting, constipation, absent anal opening is the common symptoms at presentation. Anorectal malformation is the leading cause of intestinal obstruction in neonates.

\section{REFERENCES}

1. Adejuyigbe O, Jeje EA, Owa J, Adeoba EA. Neonatal intestinal obstruction in Ile Ife, Nigeria. Niger Med J. 1992;22:24-8

2. Wyllie R. 'Intestinal atresia, stenosis and malrotation', In: Kliegman RM, Behrman RE, Jenson HB, Stanton BF (editors) Nelson's textbook of paediatrics, $18^{\text {th }}$ ed, vol-2, Philadelphia, Saunders-Elseiver. 2008:1558-62.

3. Adeniran JO, Odebode TO. Congenital malformations in paediatric and neurosurgical practices: Problems and pattern (A preliminary report). Sahel Med J. 2005;8:4-8

4. Smith GHH and Glasson M. Intestinal atresia: factors affecting survival, Aust NZ J Surg. 1989;59:151-56

5. Kimura K. Bilious vomiting in the newborn: rapid diagnosis of intestinal obstruction. Am Fam Physicean May2000;61(9):2791-8

6. Yamashita H, Kato H, Uyama S, Kanata T, Nishizawa F, Kotegawa H. Laparoscopic repair of intestinal malrotation complicated by midgut volvulous. Surg Endosc. 1999;13:1160-2
7. Kumaran N, Shankar KR, Lloyd DA, Losty PD. Trends in the management and outcome of jejunoileal atresia. Eur J Paediatr Surg. 2002;2:163-7

8. Spitz L. Neonatal intestinal obstruction and intussusceptions in children, In: Schwartz SI and Ellis H (editors) Maingots abdominal operations, $8^{\text {th }}$ edition, and vol.2, New York: AppletonCentury-croft. 1985;1054-62

9. Ameh EA, Chirdan LB. neonatal intestinal obstruction in Zaria, Nigeria. East Afr Med J. 2000;77:510-3

10. Nasir GA, Rahaman S, Kadim AH. Neonatal intestinal obstruction. East Meduterr Health J. 2000;6:187-93

11. Uba AF, Edino ST, Yakubu AA, Sheshe AA. Childhood intestinal obstruction in northwestern Nigeria. West Afr J Med. 2004;23:314-8

12. Sowande OA, Ogundoye OO, Adejuyingbe $\mathrm{O}$. Pattenr and factors affecting management outcome of emergency surgery in Ile Ife, Nigeria. Surg Pract. 2007;11:71-5

13. Gangopadhyay AN, Sinha CK, Sahoo SP, Gopal SC, Gupta DK, Sharma LB, division of paediatric surgery, Institute of Medical Sciences, Benaras Hindu University, Varanasi-221005. Neonatal intestinal obstruction: 10 years review of 765 cases, Journal of Indian association of Paediatric Surgeons. 1996 Jan-Mar;1:29-32

14. Saha AK, Ali MB. Neonatal intestinal obstruction: patterns, problems and outcome; Bang Med J(Khulna). 2012;45:6-10

15. Osarumwense DO, Jonathan CO. Neonatal intestinal obstruction in Benin, Nigeria: Department of surgery, Paediatric surgery unit, University of Benin Teaching Hospital, Benin city, Nigeria. 2009;6(2):98-101. 